\title{
Review of Social Media Influence on Software Development
}

\author{
Gulshan Nematova ${ }^{1 \mathrm{a}}$, Mobashar Rehman ${ }^{1 \mathrm{~b}}$, Aamir Amin ${ }^{1 \mathrm{c}}$, Manzoor Ahmed Hashmani \\ RECEIVED ON 21.05.2019, ACCEPTED ON 23.08.2019
}

\begin{abstract}
The Software Development (SD) process requires collaboration and sharing of information in order to achieve the best results required and Social Media (SM) has helped this process immensely. SM is frequently utilized by programmers to strengthen their SD tools. In particular, communication is a key component in collaborative development, when designing large-scale software. An engineer can ask his colleagues around the world for help in solving problems or contact users for feedback. However, there is still a need to do research about the benefits as well as limitation of usage of SM in SD process. This study examines research conducted from 2009 until 2019 to help the researchers as well as businesses to learn more about the relation between SM and SD. Inclusion and exclusion criteria is imposed to sort out the research done during the mentioned time period. Type of data extracted from the selected papers includes authors' name(s), title of the paper, year of publication, type of publication, country of origin, method used, data analysis, study setting and data collection approach. Furthermore, this paper answers to the questions posed in the study, such as what are the potential limitations of using SM for SD, and what reasons are given by the organizations for utilization of SM for SD. This paper provides a systematic literature review of 31 studies on SM and SD.
\end{abstract}

Key Words: Social Media, Software Development, Software Engineering

\section{INTRODUCTION}

$\mathrm{S}$ $M$ has made a huge impact on how the businesses communicate with their customers. It is inexpensive and yet very effective way to approach and collaborate with others. By collaborating, businesses have more clear idea about the needs of their customers. This helps them immensely to improve their products or services [1].

When it comes to software engineering, there is a wellrecognized need to support tools for formal and informal activities [2]. Developers today widely use SM to improve their SD tools [3]. Especially, in collaborative development, communication is the key component. When designing larger software, an engineer can ask help from his colleagues from around the world to solve an issue, if it comes up or gets in touch with the users for feedback [4]. If we want to see this issue more broadly, according to Ali et. al. [5], Global Software Development (GSD) is also facing same challenges. For instance, in communication, any mishaps might happen while exchanging information. When working in teams there is always a challenge of task awareness and contribution to the project, and lastly, control and management of the project.

SD research is expanding and there is increasing use of Systematic Literature Reviews (SLRs) to organize the literature. The SLR is a way to synthesize available research by observing a comprehensive, predefined bias reduction procedure. Guidelines have been

${ }^{1}$ Faculty of Information and Communication Technology, Universiti Tunku Abdul Rehman (UTAR), Kampar, Malaysia. Email: ${ }^{a}$ nematova.gulshan @ gmail.com (Corresponding Editor), ${ }^{\text {m } m o b a s h a r @ u t a r . e d u . m y, ~}$ caamir@utar.edu.my.

${ }^{2}$ Department of Computer nd Information Sciences, Centre for Research in Data Science (CERDAS), Universiti Teknologi PETRONAS, Seri Iskander, Malaysia. Email: manzoor.hashmani@utp.edu.my

This is an open access article published by Mehran University of Engineering and Technology, Jamshoro under CC BY 4.0 International License. 
developed for the application of SLRs within SD, and numerous SLRs have been published on SD and related topics [6].

However, the comprehensive and systematic research on the role of SM in SD is rare despite the SM's importance. This paper's motivation is to provide a comprehensive and useful insight into the SM effect on SD. To implement SM tools effectively, a detailed understanding of SM limitations and benefits in the context of SD is necessary for software developers. Therefore, authors of this study define following research questions:

RQ1: How many research papers have been published on SM use for SD?

RQ2: What are the purposes of using SM for SD?

RQ3: What are the limitations of SM for SD?

\section{RESEARCH METHODOLOGY}

The objective of this SLR is to synthesize available data in fair, rigorous and open manner. After defining the research questions, here are the next steps to be taken in SLR [6]:

- the search process, including search strings and other search criteria,

- inclusion and exclusion criteria

- the selection process

- the data extraction process

- data synthesis

\subsection{Search Process}

A wide search process was performed to pinpoint articles published related to our topic, combining automated and manual search to expand coverage. All the collected research articles were published between January 2009 and March 2019. This process used the following search engines and indexing systems: Google Scholar, Springer Link, Science Direct, IEEE Explore, ACM Digital Library, Scopus, EI Compendex and Citeseer. For manual search, the following libraries were used: ACM Computer Surveys, ACM Transactions on Software Engineering Methodologies, Software Practice and Experience, Empirical Software Engineering Journal and Information and Software Technology.
Search terms used were: ("software development" OR "software engineering" OR "software process" OR "software development phases" OR "software development lifecycle" OR "software planning" OR "software testing" OR "software analysis" OR "software maintenance" OR "software design" OR "software quality" OR "software configuration management" OR "software validation" OR "software verification") AND ("social media" OR "new media" OR "participatory media" OR "user-generated content" OR Facebook OR MySpace OR Twitter OR YouTube OR Second Life OR LinkedIn OR wiki* OR blog* OR "Web 2.0" OR "online social network" OR "social networking").

Necessary adjustments were made according to the syntax of the search engines.

\subsection{Inclusion Criteria}

The research used the following inclusion criteria:

- $\quad$ include studies published between January 2009 and March 2019 (including these dates).

- $\quad$ include studies related to SD

- include studies related to SM

- the main objective of the research article is the usage of SM in SD

The number of citations for the selected studies was not part of inclusion criteria. The reason not to include this criterion is that it will further reduce the number of studies used for this paper. Irrespective of how many times a paper is cited, if the paper is related to SM and $\mathrm{SD}$, it was included in this study.

\subsection{Exclusion Criteria}

The research used the following exclusion criteria:

- Exclude duplicates

- Exclude studies published in different languages (other than English)

- Exclude keynotes, lab reports, presentations and tutorial summaries

- Exclude studies which are not related to SD process and SM. 


\subsection{Paper Selection}

After extracting the research articles from the search, they were evaluated considering the title and the abstract of the papers. Afterwards all the papers which were not relevant to the topic were rejected. Next based on the inclusion and exclusion criteria the rest of the papers were either rejected or selected. After the abovementioned steps, 31 papers were chosen as relevant to the topic. To tackle the issue of collaboration bias and reliability issues, studies published in journals and conferences were considered for this research.

\subsection{Data Extraction}

The title of the paper, authors name, publication venues and year of publication was extracted during the first phase. In the next phase, following details were extracted and compared:

- $\quad$ type of the study conducted

- number of respondents

- research questions were explored

- factors for SD

- factors for SM

- limitations

- future works

\section{RESULTS}

In this section, authors report the findings in relation to each of the research questions. After removing studies based on the added timeframe, the first screening resulted in the retention of 71,796 studies for a more indepth review of the abstract. Furthermore, studies were removed based on their tittle, abstract and keywords. Finally, duplicates were removed and only 31 studies were selected for the literature review as shown in Table 1. Table 2, display the extraction categories used for this research paper.

In addition to the databases mentioned above, below are the other journal databases, which were searched for related research articles:

- Journal of Systems and Software

- IEEE Transactions on Software Engineering

- IEEE Software

\begin{tabular}{|c|c|c|c|}
\hline \multicolumn{4}{|c|}{$\begin{array}{l}\text { TABLE 1: SUMMARY OF DATABSES AND } \\
\text { NUMBER OF STUDENTS IDENTIFIED }\end{array}$} \\
\hline Databases & Studies & $\begin{array}{c}\text { Adding } \\
\text { Timeframes } \\
\text { 2009-2019 }\end{array}$ & $\begin{array}{c}\text { Selected based } \\
\text { on the Abstract, } \\
\text { title and } \\
\text { keywords }\end{array}$ \\
\hline $\begin{array}{l}\text { Google } \\
\text { Scholar }\end{array}$ & 18,300 & 18,300 & 6 \\
\hline $\begin{array}{l}\text { Springer } \\
\text { Link }\end{array}$ & 2,207 & 2,201 & 4 \\
\hline Citeseer & 178,058 & 48,237 & 0 \\
\hline $\begin{array}{c}\text { Science } \\
\text { Direct }\end{array}$ & 936 & 934 & 3 \\
\hline Scopus & 431 & 431 & 20 \\
\hline Total & 201,632 & 71,796 & 33 \\
\hline \multicolumn{3}{|c|}{$\begin{array}{c}\text { After removing } \\
\text { duplications, in total }\end{array}$} & 31 \\
\hline
\end{tabular}

\begin{tabular}{|c|c|l|}
\hline \multicolumn{1}{|c|}{ TABLE 2: CATEGORIES USED IN EXTRACTING AND } \\
ANALYZING DATA
\end{tabular}


- Communications of the ACM

- ACM Computer Surveys

- ACM Transactions on Software Engineering Methodologies

- $\quad$ Software Practice and Experience

- Empirical Software Engineering Journal

- Information and Software Technology

Due to irrelevance of the articles or after removing the duplicates, no results were found.

RQ2: What are the purposes of using SM for SD?

According to the information collected from papers, there are number of purposes of using SM for SD. Most common purpose was found to be Collaboration. When developing software, it is important to have easier access or communication channel with other stakeholders using SM, like other software developer or management. The other purpose is Knowledge Management, it is crucial for any organization or software developers to have access to the knowledge and being able to share it with others using SM. Customers are the center of any project, as it is easier to develop any software if developer could get in touch with the customers using SM. Lastly, SM is great productivity tool, as it helps employees to manage their formal and informal affairs. Further details are mentioned in Table 3.

RQ3: What are the limitations of SM for SD?

According to the collected research papers, main limitation for SM usage for SD is having lack of knowledge about SM. Most authors indicate that there is a gap of knowledge to be filled in order to have best use of SM for SD. Another limitation of SM for SD is distractions while using SM as mentioned in Table 4. Employee might get too involved with informal issues and entertainment rather than only focusing on the given tasks. Some authors note that privacy issues and intellectual property issues are worth considering while using SM for SD, as SM usage might end up harming the SD rather than assisting.

Additional Data Collected: The findings show that $69 \%$ of all collected research papers used Empirical Studies as a research methodology. Theoretical Study and Literature Review methodologies were $17 \%$ and $14 \%$ respectively.

\begin{tabular}{|c|c|c|c|c|}
\hline \multicolumn{5}{|c|}{$\begin{array}{l}\text { TABLE 3: REFERENCES FOR PURPOSES OF USING } \\
\text { SM ACCORDING TO THE SELECTED YEARS }\end{array}$} \\
\hline Year & KM & $\mathrm{C}$ & CRM & $\mathrm{PT}$ \\
\hline 2009 & [7] & [7] & - & - \\
\hline 2010 & - & $\begin{array}{c}{[4,22,} \\
23]\end{array}$ & {$[4,31]$} & {$[2,23,31]$} \\
\hline 2011 & - & - & [1] & 0 \\
\hline 2012 & [8-10] & [8-10] & - & [9] \\
\hline 2013 & $\begin{array}{r}{[11,} \\
12]\end{array}$ & $\begin{array}{c}{[12,} \\
24,25]\end{array}$ & $\begin{array}{l}{[24,} \\
32]\end{array}$ & {$[11,32,33]$} \\
\hline 2015 & [13] & - & - & - \\
\hline 2016 & - & {$[26,27]$} & [26] & - \\
\hline 2017 & $\begin{array}{c}{[5,14,} \\
16]\end{array}$ & $\begin{array}{c}{[14,16,} \\
28]\end{array}$ & - & {$[14,28]$} \\
\hline 2018 & $\begin{array}{l}{[16-} \\
20]\end{array}$ & $\begin{array}{c}{[17,20,} \\
29,30]\end{array}$ & - & {$[16,18]$} \\
\hline 2019 & [21] & {$[21]$} & - & {$[21,34]$} \\
\hline \multicolumn{5}{|c|}{$\begin{array}{l}\text { Note: } \\
\text { KM = Knowledge Management } \\
\mathrm{C}=\text { Collaborations } \\
\text { CRM = Customer Relationship Management } \\
\text { PT = Productivity Tools }\end{array}$} \\
\hline
\end{tabular}

According to the data collected, out of 31 studies the highest number of studies were conducted in UK, followed by USA, Denmark and India. Other papers were based on Canada, New Zealand, Malaysia and others as shown in Fig.1.

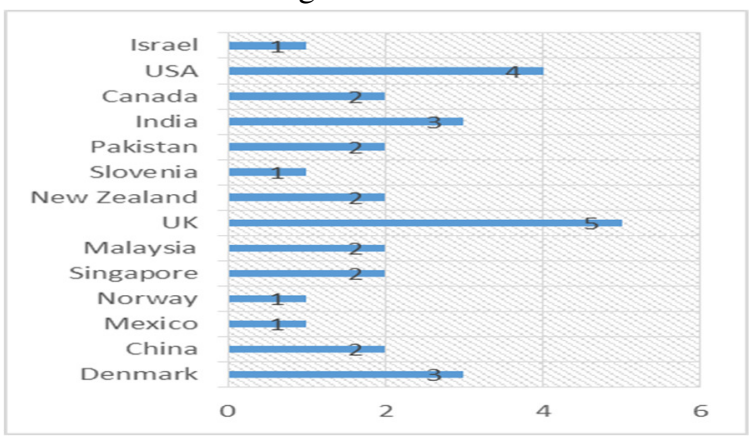

FIG. 1: COUNTRY OF ORIGINS

When it come to the type of publications used for the papers Journal papers got the top ranking followed by Conference and Workshop papers as shown in Fig. 2.

As in Fig.3, most of the authors, 42\%, used 


\begin{tabular}{l} 
TABLE 4. REFERENCES FOR LIMITATIONS OF USING SM ACCORDING TO THE SELECTED \\
YEARS \\
\hline
\end{tabular}

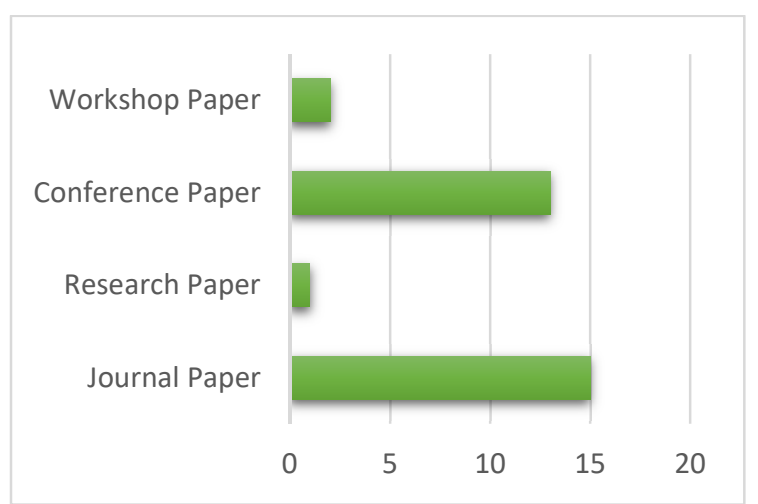

FIG. 2: TYPE OF PUBLICATIONS

quantitative data analysis for their research papers, some of the papers did not reveal about the data analysis methods. Qualitative analysis used was only $10 \%$ out of all the papers. Others used mixed method of data analysis, both quantitative and qualitative analysis were used.

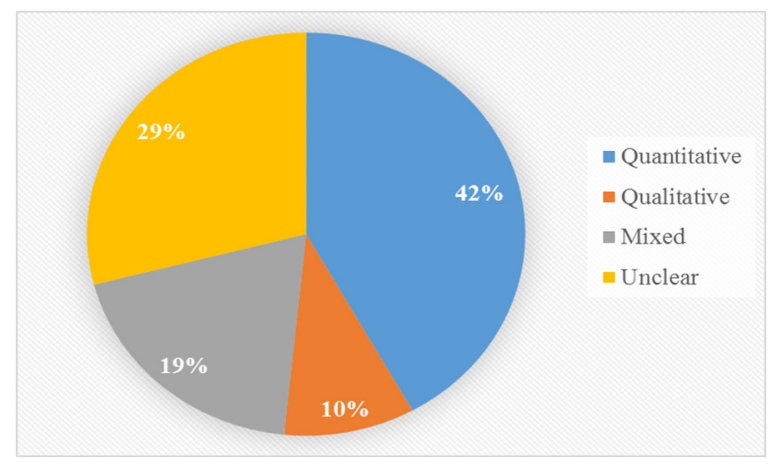

FIG. 3. DATA ANALYSIS USED

Table 5 entails the additional information retrieved during the data analysis. From this information we can conclude that most of the study settings were Industry settings, the rest were academic settings, and some of the papers did not mention the type of settings used. When it comes to data collection, most of the authors used Questionnaire or Archival technique to retrieve the data needed. Additionally, to collect data authors used Interviews, Observations and Experiments.

\section{DISCUSSIONS}

In this section, answers to the research questions are discussed.

RQ1: How many papers are there on SM using for $\mathrm{SD}$ ?

During the review process, 31 studies were analyzed. Based on our inclusion and exclusion criteria, which covered papers written from 2009 until 2019, most of the studies were published in the year 2013 and 2018. Out of which, 31 studies were selected for the literature review. This number includes Empirical Studies, theoretical Studies and Literature Reviews as shown in Fig.4. Authors excluded keynotes, lab reports, presentations and tutorial summaries. Additionally, studies published in different languages (other than English) and not related SM or SD were also excluded.

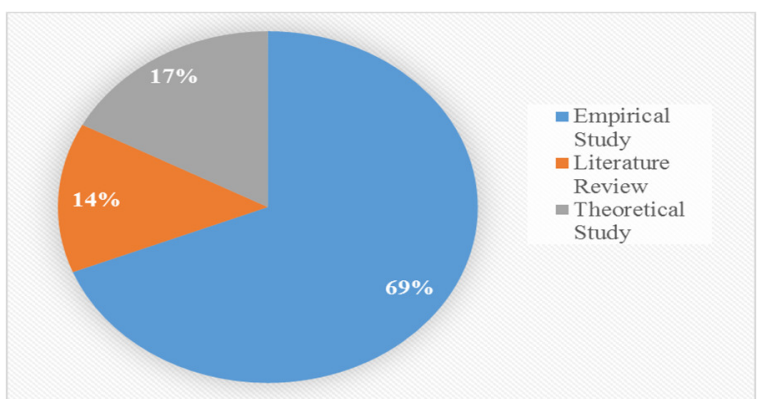

FIG. 4. METHODS USED IN THE ACCEPTED STUDIES

RQ2: What are the purposes of using SM for SD?

Knowledge Management: Effective knowledge exchange among software developers is crucial in competitive market of SD and SM. It is seen extremely important for the developer resource because this provides updated documentation and high-quality answers as well as dialogue opportunities.

Collaboration: SM is also a critical factor in collaborative development, especially when designing large scale modern software systems that have to meet the needs of a diverse group of users and stakeholders. Mehran University Research Journal of Engineering and Technology, Vol. 39, No. 3, July 2020 [p-ISSN: 0254-7821, e-ISSN: 2413-7219] 


\begin{tabular}{|c|c|c|c|c|c|}
\hline \multicolumn{6}{|c|}{ TABLE 5. ADDITIONAL DATA REGARDING TO THE COLLECTED PAPERS } \\
\hline No. & Author & Method & Data Analysis & Study Setting & Data Collection \\
\hline 1. & Sarka and Ipsen [35] & $\begin{array}{l}\text { Literature } \\
\text { Review }\end{array}$ & Quantitative & Academic & Archival \\
\hline 2. & Zhang et. al. [26] & \multirow{4}{*}{ Empirical Study } & & Industry & \\
\hline 3. & Juárez-Ramírez et. al. [11] & & Unclear & Academic & \\
\hline & & & & & \\
\hline 4. & Andersen and Mørch [32] & & Mixed & Industry & $\begin{array}{l}\text { Interview and } \\
\text { Questionnaire }\end{array}$ \\
\hline 5. & Giuffrida and Dittrich [12] & $\begin{array}{c}\text { Literature } \\
\text { Review }\end{array}$ & Mixed & Industry & Archival \\
\hline 6. & Cheliotis [7] & $\begin{array}{l}\text { Literature } \\
\text { Review }\end{array}$ & Unclear & Academic & Archival \\
\hline 7. & Wong et. al. [8] & \multirow{9}{*}{ Empirical Study } & \multirow{2}{*}{ Unclear } & Academic & Experiment \\
\hline 8. & Brooker [34] & & & Industry & Observation \\
\hline 9. & Chen et. al. [21] & & \multirow{5}{*}{ Quantitative } & \multirow{7}{*}{ Industry } & \multirow{4}{*}{ Questionnaire } \\
\hline 10. & Yasir et. al. [17] & & & & \\
\hline 11. & Rainer \& Williams [29] & & & & \\
\hline 12. & Sharma et. al. [30] & & & & \\
\hline 13. & Forsgren and Byström [28] & & & & Interviews \\
\hline 14. & Trkman and Trkman [18] & & \multirow{2}{*}{ Mixed } & & $\begin{array}{l}\text { Questionnaire } \\
\text { and Interviews }\end{array}$ \\
\hline 15. & Mughal et. al. [19] & & & & $\begin{array}{l}\text { Experiment and } \\
\text { Questionnaire }\end{array}$ \\
\hline 16. & Mushtaq et. al. [20] & $\begin{array}{c}\text { Theoretical } \\
\text { Study }\end{array}$ & Unclear & Academic & Archival \\
\hline 17. & Mukherjee and Natrajan[14] & \multirow{2}{*}{ Empirical Study } & \multirow{5}{*}{ Quantitative } & Academic & Experiment \\
\hline 18. & Sagar and Saha [15] & & & Industry & Questionnaire \\
\hline 19. & Sarka and Ipsen [16] & $\begin{array}{c}\text { Literature } \\
\text { Review }\end{array}$ & & Unclear & Archival \\
\hline 20. & Storey et. al. [27] & \multirow{2}{*}{ Empirical Study } & & Industry & \multirow{2}{*}{ Questionnaire } \\
\hline 21. & Wu et. al. [13] & & & Unclear & \\
\hline 22. & van Osch and Coursaris [24] & $\begin{array}{c}\text { Theoretical } \\
\text { Study }\end{array}$ & Unclear & Academic & Archival \\
\hline 23. & Correa and Sureka [25] & \multirow{3}{*}{ Empirical Study } & \multirow[b]{2}{*}{ Mixed } & \multirow{3}{*}{ Industry } & Questionnaire \\
\hline 24. & Black et. al. [22] & & & & $\begin{array}{c}\text { Questionnaire, } \\
\text { Interview }\end{array}$ \\
\hline 25. & Black et. al. [23] & & Qualitative & & Observation \\
\hline 26. & Storey et. al. [4] & $\begin{array}{c}\text { Theoretical } \\
\text { Study }\end{array}$ & Quantitative & Academic & Archival \\
\hline 27. & Bajic et. al. [1] & Empirical Study & Mixed & \multirow{2}{*}{ Industry } & $\begin{array}{l}\text { Questionnaire } \\
\text { and Interviews }\end{array}$ \\
\hline 28. & Adetola et. al. [33] & $\begin{array}{c}\text { Theoretical } \\
\text { Study }\end{array}$ & \multirow{2}{*}{ Unclear } & & Observation \\
\hline 29. & Begel et. al. [31] & $\begin{array}{c}\text { Theoretical } \\
\text { Study }\end{array}$ & & Academic & Archival \\
\hline 30. & Dabbish et. al. [9] & \multirow{2}{*}{ Empirical Study } & \multirow{2}{*}{ Qualitative } & \multirow{2}{*}{ Industry } & Interviews \\
\hline 31. & Zagalsky et. al. [10] & & & & Experiment \\
\hline
\end{tabular}

Customer Relationship Management: Customer is the main asset of many companies, whose input has to be leveraged, allowing continual learning and improvement of SD. And SM is best way of reaching out to the customers.

Mehran University Research Journal of Engineering and Technology, Vol. 39, No. 3, July 2020 [p-ISSN: 0254-7821, e-ISSN: 2413-7219]
Productivity Tools: Social media help influences individual and team performance by giving employees tools to improve in formal and informal SD environment. 
RQ3: What are the limitations of SM for SD?

Lack of knowledge of SM: Limited knowledge exists about use of SM for developers, due to lack of experience regarding SM. As well as pace and aims of information sharing, un-optimized functionality, caused inconsistencies in use and adoption. Companies do not yet fully understand it

how to effectively take advantage of it for improving product innovation process.

Privacy Issues: Privacy and security, as well as its influence on productivity and product quality is concern for SD organizations.

Intellectual Property: The risk of duplication of the intellectual property as well as recreating different versions of the same item in order to abuse intellectual property.

Distractions: Employees who are utilizing SM, sometimes can be distracted by personal use and interests. Employees immerse in using social media for fun but overlook work-related purposes.

\section{STUDY LIMITATIONS AND FUTURE WORKS}

Regarding to the limitations of this study, even though thorough search has been conducted, due to increasing number of studies in Software Engineering and papers having very similar areas, it cannot be claimed to have obtained all the research articles in this field of study. Also, there might be other papers which are not available through open access.

The future work might include other communication and collaboration ways that can simplify the collaborative development process. Especially, Web 3.0 features would be an unexplored topic. Social media is constantly developing, and therefore researchers struggles to keep up with its progress. There should be a new framework to make it easier for researchers to review any given topic.

\section{CONCLUSIONS}

In this paper, authors targeted to deliver a comprehensive overview of papers focused on to improve SD via SM. Besides, purpose was to determine use of SM for SD and limitations to assist future research agendas.

Kitchenham and Charters guidelines were followed for the Research Methodology. Firstly, papers were searched using search strings. Next papers were selected according to the inclusion and exclusion criteria, followed by the selection process, where title of the paper, name of the author, methods used were extracted. Lastly, authors looked for the answers to research questions from the selected papers.

Based on this review, there are number of motivating factors of choosing SM for SD as an organizational tool. It is a collaboration tool between the organization and the customers. Usage of SM positively affects the organizations as easier and cheaper communication is carried out through this channel. Another positive outcome of using SM is knowledge management. Social media is fastest way of getting latest information needed for growth of the company. Lastly, it is also suitable as a tool which enhances productivity and customer relationship management, which has huge positive impact for the improvement of the SD of organizations.

However, studies showed that there might be some factors which discourage use of SM for SD. For example, lack of knowledge is one of the factors. In order to fully adopt SM, firstly the employee must be trained to cope with this tool. Some companies are concerned with SM being a distractive tool because employees may use it for personal reasons rather than professional use during office hours, and others hold back on utilizing SM for SD for intellectual property and privacy related issues as well.

Even though, there are some limitations of using SM for SD, like lack of knowledge, privacy issues or potential distraction of usage, there are still way more benefits of using SM in order to enhance SD, as well as business performance of the organizations.

\section{ACKNOWLEDGEMENT}

This work was supported by Universiti Tunku Abdul Rahman, Malaysia, under the grant research fund (UTARRF), February 2016 - January 2017.

\section{REFERENCES}

[1] Bajic, D., and Lyons, K., "Leveraging Social Media to Gather User Feedback for Software Development", Proceedings of 2nd International Workshop on Web 2.0 for Software Engineering, pp. 1-6, 2011.

[2] Robert, K.E., and Lynn, A. Streeter. "Coordination in software development." Communications of the ACM, Vol. 38, No. 3, Mehran University Research Journal of Engineering and Technology, Vol. 39, No. 3, July 2020 [p-ISSN: 0254-7821, e-ISSN: 2413-7219] 
1995.

[3] Ahmadi, N., Jazayeri, M., Lelli, F., and Nesic, S., "A survey of social software engineering." Proceedings of 23rd IEEE/ACM International Conference on Automated Software EngineeringWorkshops, pp. 1-12. IEEE, 2008.

[4] Storey, M.A., Treude, C., van Deursen, A. and Cheng, L.T., "The impact of social media on software engineering practices and tools." Proceedings of the FSE/SDP workshop on Future of software engineering research, $\mathrm{pp}$. 359-364. ACM, 2010.

[5] Ali, S., Iqbal, N. and Hafeez, Y., "Towards Requirement Change Management for Global Software 5Development using Case Base Reasoning." Mehran University Research Journal of Engineering and Technology, 37, No. 3, 2018.

[6] Kitchenham, B. and Charters, S., "Guidelines for performing systematic literature Reviews in Software Engineering", 2007.

[7] Cheliotis, G., "From open source to open content: Organization, licensing and decision processes in open cultural production." Decision Support Systems, Vol. 47, no. 3, 2009.

[8] Wong, C.Y., Khong, C.W. and Chu, K., "Interface design practice and education towards mobile apps development." Procedia-Social and Behavioral Sciences, Vol. 51, 2012.

[9] Dabbish, L., Stuart, C., Tsay, J. and Herbsleb, J., "Social coding in GitHub: transparency and collaboration in an open software repository." Proceedings of the ACM 2012 conference on computer supported cooperative work, pp. 1277-1286. ACM, 2012.

[10] Zagalsky, A., Barzilay, O. and Yehudai, A., "Example overflow: Using social media for code recommendation." Proceedings of the Third International Workshop on Recommendation Systems for Software Engineering, pp. 38-42. IEEE Press, 2012.

[11] Juárez-Ramírez, R., Pimienta-Romo, R. and Ocegueda-Miramontes, V., "Using social networks for integrating a tacit knowledge repository to support the performance of software development teams." Proceedings of International Symposium on Integrated Uncertainty in Knowledge Modelling and Decision Making, pp. 167-179. Springer, Berlin, Heidelberg, 2013.

[12] Giuffrida, R. and Dittrich, Y., "Empirical studies on the use of social software in global software development-A systematic mapping study." Information and Software Technology, Vol. 55, no. 7, 2013.

[13] Wu, L., Pa, N.C., Abdullah, R. and Rahman, W.N.W.A., "An analysis of knowledge sharing behaviors in requirement engineering through social media." Proceedings of 9th Malaysian Software Engineering Conference (MySEC), pp. 93-98. IEEE, 2015.

[14] Mukherjee, D. and Natrajan, N.S., "Comparative analysis of social media tool used in software projects deploying virtual teams." Vision, Vol. 21, No. 4, 2017.

[15] Sagar, K. and Saha, A., "Qualitative usability feature selection with ranking: a novel approach for ranking the identified usability problematic attributes for academic websites using data-mining techniques." Humancentric Computing and Information Sciences, 7, No. 1, 2017.

[16] Sarka, P. and Ipsen, C., "Knowledge sharing via social media in software development: a systematic literature review." Knowledge Management Research \& Practice, 15, No. 4, 2017.

[17] Yasir, M., Michael, K., Savarimuthu, B.T.R. and Licorish, S.A., "Formal in the Informal: A Multi-Level Analysis of Core Python Developers' Tweets." Proceedings of 25th Australasian Software Engineering Conference (ASWEC), pp. 151-160. IEEE, 2018.

[18] Trkman, M. and Trkman, P., "A framework for increasing business value from social media." Economic research-Ekonomska istraživanja, Vol. 31, No. 1, 2018.

[19] Mughal, S., Abbas, A., Ahmad, N. and Khan, S.U., "A Social Network Based Process to Minimize In-Group Biasedness During Requirement Engineering." IEEE Access, Vol. 6, 2018.

[20] Mushtaq, H., Malik, B.H., Shah, S.A., Siddique, U.B., Shahzad, M. and Siddique, I., "Implicit and Explicit Knowledge Mining of Crowdsourced Communities: Architectural and Technology Verdicts." International Journal Of Advanced Computer Science And Applications, Vol. 9, no. 1, 2018.

[21] Chen, X., Wei, S., Sun, C. and Liu, Y., "How Technology Support for Contextualization Affects Enterprise Social Media Use: A Media System Dependency Perspective." IEEE Transactions on Professional Communication, 2019. 
[22] Black, S., Harrison, R. and Baldwin, M., "A survey of social media use in software systems development." Proceedings of the 1st Workshop on Web 2.0 for Software Engineering, pp. 1-5. ACM, 2010.

[23] Black, S. and Jacobs, J., "Using Web 2.0 to improve software quality." Proceedings of the 1st Workshop on Web 2.0 for Software Engineering, pp. 6-11. ACM, 2010.

[24] van Osch, W. and Coursaris, C.K., "Organizational social media: A comprehensive framework and research agenda." Proceedings of 46th Hawaii International Conference on System Sciences, pp. 700-707. IEEE, 2013.

[25] Correa, D. and Sureka, A., "Integrating issue tracking systems with community-based question and answering websites." Proceedings of 22nd Australian Software Engineering Conference, pp. 88-96. IEEE, 2013.

[26] Zhang, Y., Wang, H., Yin, G., Wang, T. and Yu, Y., "Social media in GitHub: the role of@-mention in assisting software development." Science China Information Sciences, Vol. 60, no. 3, 2017.

[27] Storey, M.A., Zagalsky, A., Figueira Filho, F., Singer, L. and German, D.M., "How social and communication channels shape and challenge a participatory culture in software development." IEEE Transactions on Software Engineering, 43, no. 2, 2016.

[28] Forsgren, E. and Byström, K., "Multiple social media in the workplace: Contradictions and congruencies." Information Systems Journal, 28, no. 3, 2018. [29] Rainer, A. and Williams, A., "Using blog articles in software engineering research: benefits, challenges and case-survey method." Proceedings of 25th Australasian Software Engineering Conference (ASWEC), pp. 201-209. IEEE, 2018.

[30] Sharma, A., Tian, Y., Sulistya, A., Wijedasa, D. and Lo, D., "Recommending Who to Follow in the Software Engineering Twitter Space." ACM Transactions on Software Engineering and Methodology (TOSEM), 27, no. 4, 2018.

[31] Begel, A., DeLine, R. and Zimmermann, T., "Social media for software engineering." Proceedings of the FSE/SDP workshop on Future of software engineering research, pp. 33-38. ACM, 2010.

[32] Andersen, R. and Mørch, A.I., "Get satisfaction: Customer engagement in collaborative software development." Proceedings of International Symposium on End User Development, pp. 235-240. Springer, Berlin, Heidelberg, 2013.

[33] Adetola, A., Li, S., Rieple, A., and Ñ́guez, T.-M., "Linking social media, intelligent agents and expert systems for formulating open innovation strategies for software development." WSEAS, 2013.

[34] Brooker, P., "My unexpectedly militant bots: A case for Programming-as-Social-Science." The Sociological Review, 2019.

[35] Sarka, P. and Ipsen, C., "Knowledge sharing via social media in software development: a systematic literature review." Knowledge Management Research \& Practice, Vol. 15, No. 4, 2017. 